Article

\title{
Analysis of Dual-Polarimetric Radar Variables and Quantitative Precipitation Estimators for Landfall Typhoons and Squall Lines Based on Disdrometer Data in Southern China
}

\author{
Yonghua Zhang ${ }^{1,2,3}{ }^{\oplus}$, Liping Liu ${ }^{2, *}$, Shuoben Bi ${ }^{1}\left(\mathbb{D}\right.$, Zhifang $\mathrm{Wu}^{4}$, Ping Shen ${ }^{5}$, Zhenlang Ao ${ }^{3}$, \\ Chao Chen ${ }^{4}$ and Yang Zhang ${ }^{2,6}$ \\ 1 School of Geographic science, Nanjing University of Information Science \& Technology, Nanjing 210044, \\ Jiangsu, China; zhangyh@grmc.gov.cn (Y.Z.); bishuoben@163.com (S.B.) \\ 2 State Key Laboratory of Severe Weather, Chinese Academy of Meteorological Sciences, Beijing 100081, China; \\ zhangyang_cams@163.com \\ 3 Guangdong Meteorological Observation Data Center, Guangzhou 510641, Guangdong, China; \\ zlao2005@163.com \\ 4 Guangdong Meteorological Observatory, Guangzhou 510641, Guangdong, China; \\ zhifang_wu@tom.com (Z.W.); chenchao@grmc.gov.cn (C.C.) \\ 5 Guangdong Emergency Early Warning Release Center (Guangdong Weather Modification Centre), \\ Guangzhou 510641, Guangdong, China; shenping@grmc.gov.cn \\ 6 School of Atmospheric Physics, Nanjing University of Information Science \& Technology, Nanjing 210044, \\ Jiangsu, China \\ * Correspondence: liulp@cma.gov.cn; Tel.: +86-010-6840-7430
}

Received: 7 November 2018; Accepted: 8 January 2019; Published: 14 January 2019

check for updates

\begin{abstract}
Typhoon rainstorms often cause disasters in southern China. Quantitative precipitation estimation (QPE) with the use of polarimetric radar can improve the accuracy of precipitation estimation and enhance typhoon defense ability. On the basis of the observed drop size distribution (DSD) of raindrops, a comparison is conducted among the DSD parameters and the polarimetric radar observation retrieved from DSD in five typhoon and three squall line events that occurred in southern China from 2016 to 2017. A new piecewise fitting method (PFM) is used to develop the QPE estimators for landfall typhoons and squall lines. The performance of QPE is evaluated by two fitting methods for two precipitation types using DSD data collected. Findings indicate that the number concentration of raindrops in typhoon precipitation is large and the average diameter is small, while the raindrops in squall line rain have opposite characteristics. The differential reflectivity $\left(Z_{\mathrm{DR}}\right)$ and specific differential phase $\left(K_{\mathrm{DP}}\right)$ in these two precipitation types increase slowly with the reflectivity factor $\left(Z_{\mathrm{H}}\right)$, whereas the two precipitation types have different $Z_{\mathrm{DR}}$ and $K_{\mathrm{DP}}$ in the same $Z_{\mathrm{H}}$. Thus, it is critical to fit the rainfall estimator for different precipitation types. Enhanced estimation can be obtained using the estimators for specific precipitation types, whether the estimators are derived from the conventional fitting method (CFM) or PFM, and the estimators fitted using the PFM can produce better results. The estimators for the developed polarimetric radar can be used in operational QPE and quantitative precipitation foresting, and they can improve disaster defense against typhoons and heavy rains.
\end{abstract}

Keywords: landfall typhoons in Southern China; drop size distribution; QPE algorithm for specific precipitation type; PFM 


\section{Introduction}

Southern China is located in the tropical and subtropical monsoon region. Given its proximity to the South Sea, southern China experiences frequent, highly destructive typhoons [1,2]. Every year, typhoon-induced disasters cause tremendous losses in life, property, economy, and society $[3,4]$. The main factor in typhoon-induced disasters is heavy precipitation. Therefore, quantitative precipitation estimation (QPE) and quantitative precipitation foresting (QPF) need to be improved. Unfortunately, classic Z-R correlation was previously used in QPE with Doppler radars, and heavy precipitation was usually underestimated. To improve QPE, Doppler radars are being upgraded to dual-polarimetric (hereafter "dual-pol") radars in China. Dual-pol radars can detect the reflectivity factor $\left(Z_{\mathrm{H}}\right)$, the differential reflectivity factor $\left(Z_{\mathrm{DR}}\right)$, and the specific differential phase $\left(K_{\mathrm{DP}}\right)$. Particularly, the $Z_{\mathrm{DR}}$ and $K_{\mathrm{DP}}$ can be used to retrieve the drop size distribution (DSD) of raindrops, understand the physical process in precipitation, and improve QPE. In addition, the DSDs of typhoon precipitation are different from those of other precipitation types, thereby leading to the differences in QPE algorithms [5,6]. An improved QPE estimator and schemes for typhoon rainstormS-band dual-pol radars should be provided in southern China. Typhoon and squall line rainstorms are the most important disasters in South China [3,4,7-9], and the microphysical features of the two precipitation types are inconsistent. It is necessary to study the DSD characteristics and precipitation estimation algorithms of these two precipitation types. Thus, studies on QPE for the two precipitation types are of great importance for disaster prevention and mitigation in southern China.

DSD data from different precipitations and regions are used to fit the rainfall estimator for dual-pol radars [10-23]. On the basis of local DSD data, radar rainfall estimators for the C-band polarimetric radar were proposed by Aydin et al. [24] in Colorado, by Bringi et al. [16] in Okinawa, by Wang et al. [17] in Taiwan, by Gu et al. [25] in Oklahoma, by Wu et al. [26] in Jianghai, China, by Silvestro et al. [27] in Italy, and by Bringi et al. [28] in the United Kingdom, respectively, which are remarkably different. Furthermore, the estimators for S-band polarimetric radar were proposed by Aydin et al. [24] in Colorado, USA, by Ryzhkov et al. [14,15] in Oklahoma, USA, by You et al. [18] in Pukyong, Korea, by Lee et al. [29] in Montreal, Canada, and Kwon et al. [30] in Busan, Korea. When using dual-pol radar to estimate precipitation, the estimators are different from region to region. The estimator is related to the local DSD and the wavelength. Therefore, the radar rainfall estimator varies with precipitation types and regions. For a specific region and precipitation type, the estimator should be retrieved from local DSD data.

Currently, a considerable amount of research related to the development of QPE algorithm is being conducted for dual-pol radar observation based on the DSD data in China. Qiming Cai et al. [31] derived the rainfall estimator $R\left(Z_{\mathrm{H}}, Z_{\mathrm{DR}}\right)$ for the C-band digital weather radar; Hongfa Zhang et al. [32] obtained the rainfall estimator $R\left(Z_{\mathrm{H}}, Z_{\mathrm{DR}}\right)$ for the $\mathrm{C}$-band digital weather radar based on the DSDs data in northwestern China; Liping Liu et al. [33] calculated a variety of rainfall estimators for C-band radar using the gamma DSD; Jianlin Wang et al. [23] proposed rainfall estimators $R\left(Z_{\mathrm{H}}\right), R\left(Z_{H}, Z_{\mathrm{DR}}\right), R\left(K_{\mathrm{DP}}\right)$ for an S-band dual-pol radar for convective precipitation in Oklahoma, USA; Xueqian Ma et al. [34] derived the rainfall estimator for an X-band dual-pol radar based on the rain rate using a rain gauge in Pingliang, Gansu, China. Yichen Chen et al. [35] obtained the rainfall estimators for an X-band dual-pol radar by using automatic weather station data in Beijing, China, which are for convective and stratiform rain, respectively. Linlin $\mathrm{Wu}$ [26] calculated several rainfall estimators for C-band radar based on $1 D$ laser disdrometer data, $R\left(Z_{H}\right), R\left(Z_{H}, Z_{D R}\right), R\left(K_{D P}\right)$, and $R\left(K_{D P}, Z_{D R}\right)$, in the Jiang-Huai region of China. Gang Chen et al. [36] proposed rainfall estimators $R\left(Z_{\mathrm{H}}\right), R\left(Z_{H}, Z_{\mathrm{DR}}\right)$, and $R\left(K_{\mathrm{DP}}\right)$ for a C-band dual-pol radar based on 2D video disdrometer (2DVD) data in eastern China.

An investigation of the precipitation internal structures and microphysics is indispensable to improve the accuracy of QPE for typhoons. At present, studies in this field have made great progress. May et al. [37] illustrated the microphysical structures of Tropical Cyclone Ingrid by using polarized radar observations. Tokay et al. [38] investigated the characteristics of DSD in seven Atlantic typhoons over the period from 2004 to 2006 . Their findings revealed that the concentration of small and/or 
medium drops is high and the maximum drop diameter rarely exceeded $4 \mathrm{~mm}$. Bringi et al. [39] analyzed the DSD characteristics in Darwin, Australia by using dual-frequency profiler and dual-pol radar. The reflectivity factor $Z$, median volume equivalent diameter $D_{0}$, and rain rate $R$ obtained from the two observations showed great consistency. The study also concluded that mean $D_{0}$ is considerably larger in the typhoon examples than in the monsoon examples. Weiyu Chang et al. [40] analyzed the characteristics of DSD based on ground-based 2DVD and C-band polarimetric radar observation in typhoon precipitations during landfall in the western Pacific, near northern Taiwan. The study indicates that the DSDs from typhoon rain on the ocean are mainly a maritime convective type, the average mass-weighted diameter $D_{m}$ was about $2 \mathrm{~mm}$, and the average logarithmic normalized intercept $\log 10 N_{w}$ is $3.8\left(\mathrm{~mm}^{-1} \mathrm{~m}^{-3}\right)$. Baojun Chen et al. [41] analyzed the microphysical characteristics of the DSD of Typhoon Morakot (2009) during landfall and found that DSD is typically characterized by a single peak distribution. Mingjun Wang et al. [42] analyzed the microphysical characteristics and the precipitation efficiency of the rainband in Typhoon Matmo (2014) over eastern China. The study revealed that the convective precipitation in the rainband generally contains smaller drops and higher number concentrations than the typical maritime type convective precipitation described in Bringi et al. [43]. The average mass-weighted diameter $\left(D_{m}\right)$ of convective precipitation in the rainband is about $1.41 \mathrm{~mm}$, and the average logarithmic normalized intercept $\log 10 N_{w}$ is $4.67\left(\mathrm{~mm}^{-1} \mathrm{~m}^{-3}\right)$.

From the above research, we can see that QPE for non-typhoon precipitations has been greatly promoted in China. So far, QPE algorithms have not been developed for typhoon precipitation based on S-band dual-polarimetric radar in southern China. The microphysics and impacts on rainfall estimation of typhoons and squall lines have not been compared and analyzed here. The 10 sets of disdrometers are set up and operational in Guangdong Province of China, and the S-band dual-pol radar network was also constructed there. This provides imperative data support for analyzing the microphysics and developing the QPE algorithms of the landfall typhoons in southern China and assessing their effectiveness.

In this paper, DSD data for typhoon and squall line rain were collected, and the DSD features and QPE estimators were investigated using these data with two fitting methods for two precipitation types. A new piecewise fitting method (PFM) is used to develop the QPE estimators for the two precipitation types, and their effectiveness at rainfall estimation is evaluated in this study. This paper is organized as follows: Section 2 includes the data sources and methods. In Section 3, the characteristics of DSD data and the polarimetric variables are analyzed for typhoon and squall line precipitation. In Section 4, the optimal scheme of rainfall estimators for typhoons and squall lines is selected. In Section 5, the results are analyzed, discussed, and summarized, and the conclusions are drawn. In Section 5, research issues in this study are discussed, and plans for future work are outlined.

\section{DSD Dataset and Retrieval of Polarimetric Variables}

The DSD data are obtained from two kinds of disdrometer in this study: the LPA10 Automatic Disdrometer, manufactured by Beijing Metstar Radar Co. Ltd., and the Parsivel2 disdrometer, manufactured by OTT Messtechnik, Germany. The two types of disdrometer have similar observation principles, and only the classification of diameter and velocity shows variations. LPA10 can measure sizes up to about $30 \mathrm{~mm}$ and uses 64 size bins of different widths, ranging from $0.125 \mathrm{~mm}$ to $1 \mathrm{~mm}$. The smallest and largest detectable fall velocity is about 0.05 and $21 \mathrm{~m} \mathrm{~s}^{-1}$ (LAP10 Automatic Disdrometer Technical Manual, Beijing Mestar Radar Co. Ltd., 2013). Parsivel2 can measure sizes up to about $26 \mathrm{~mm}$ and uses 32 size bins of different widths, ranging from $0.125 \mathrm{~mm}$ to $3 \mathrm{~mm}$. The smallest and largest detectable fall velocity is about 0.05 and $21 \mathrm{~m} \mathrm{~s}^{-1}$, respectively $[41,44]$. The velocities of the two instruments are subdivided into 32 size bins with different widths. Both observations are recorded once per minute.

The DSD data obtained from Luogang, Baiyun, and Nanhai are observed using the LPA10 disdrometers, and the data from Nanxiong, Pingyuan, Renhua, Longchuan, Huidong, Yingde, and Gaozhou are observed using the Parsivel2 disdrometers. The locations of all disdrometers 
(ten sets) are shown in Figure 1. The specific latitude and longitude coordinates, altitude, and the abbreviated identification are shown in Table 1.

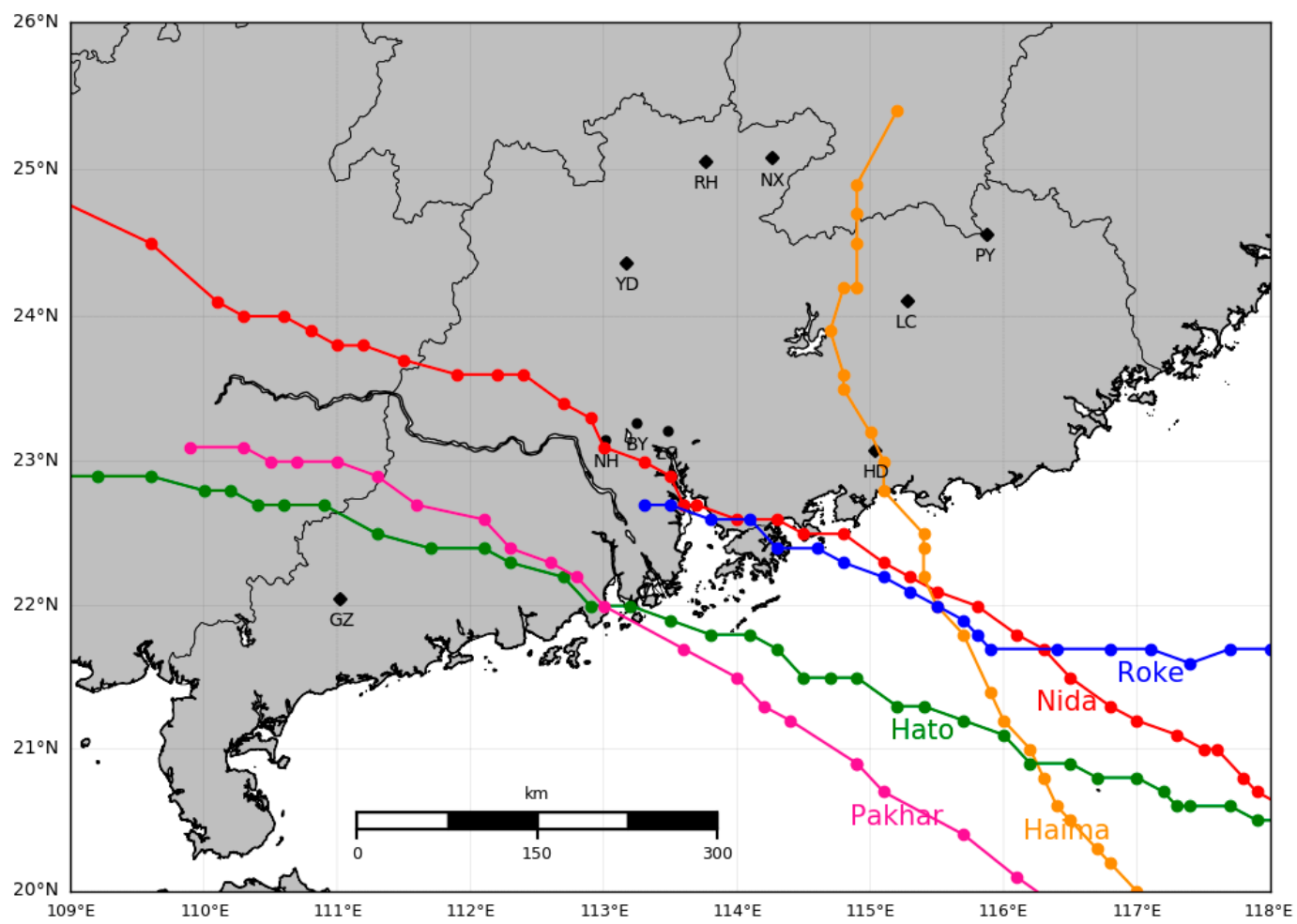

Figure 1. Location of disdrometers (black dots or black squares) and typhoon paths (colored dotted lines).

Table 1. Location of the disdrometers and their identification.

\begin{tabular}{cccccc}
\hline Location & $\begin{array}{c}\text { Longitude } \\
\left(\mathbf{(}^{\mathbf{E}} \mathbf{)}\right.\end{array}$ & $\begin{array}{c}\text { Latitude } \\
\mathbf{( \mathbf { }} \mathbf{N})\end{array}$ & $\begin{array}{c}\text { Altitude } \\
(\mathbf{m})\end{array}$ & $\begin{array}{c}\text { Instrument } \\
\text { Type }\end{array}$ & Identification \\
\hline Luogang, Guangzhou & 113.48 & 23.21 & 70.7 & LPA10 & LG \\
Baiyun, Guangzhou & 113.25 & 23.27 & 20.0 & LPA10 & BY \\
Nanhai, Foshan & 113.01 & 23.15 & 30.1 & LPA10 & NH \\
Nanxiong, Shaoguan & 114.26 & 25.08 & 149.7 & Parsivel2 & NX \\
Pingyuan, Meizhou & 115.87 & 24.56 & 200.8 & Parsivel2 & PY \\
RenHua, Shaoguan & 113.76 & 25.06 & 111.7 & Parsivel2 & RH \\
Longchuan, Heyuan & 115.28 & 24.11 & 179.6 & Parsivel2 & LC \\
Huidong, Huizhou & 115.03 & 23.08 & 86.0 & Parsivel2 & HD \\
Yingde, Qingyuan & 113.17 & 24.37 & 230.0 & Parsivel2 & YD \\
Gaozhou, Maoming & 111.02 & 22.05 & 115.0 & Parsivel2 & GZ \\
\hline
\end{tabular}

In this paper, the DSD data for five typhoons (the paths shown in Figure 1) and three squall lines in southern China during the period from 2016 to 2017 are selected. From the observation of the dual-pol radars, it can be seen there is no squall line in the five typhoon cases. Table 2 lists all detailed information including observation periods, observatory identification, and sample numbers.

To improve the data quality, QC was conducted. Measurement samples, with total raindrops fewer than 50 , rainfall intensity less than $0.5 \mathrm{~mm} / \mathrm{h}$, and the velocities with the absolute difference between measured and theoretical terminal velocities being larger than 0.6 times the theoretical terminal velocity were rejected as noises [24-26,45,46]. 
Table 2. Lists of the DSD data for typhoon and squall line events.

\begin{tabular}{|c|c|c|c|c|}
\hline Precipitation Type & Weather Event & Observation Period & Observatory (ID) & $\begin{array}{l}\text { Samples } \\
\text { (Number) }\end{array}$ \\
\hline \multirow{4}{*}{ Typhoon } & $\begin{array}{l}\text { Nida } \\
(1604)\end{array}$ & 3:00 18:00, August 2, 2016 & $\begin{array}{c}\text { LG, BY, NH, } \\
\text { NX, PY, RH, YD }\end{array}$ & 3054 \\
\hline & $\begin{array}{l}\text { Haima } \\
(1622)\end{array}$ & 12:00 21:00, October 21, 2016 & $\begin{array}{l}\text { BY, NH, NX, } \\
\text { PY, RH, YD }\end{array}$ & 1845 \\
\hline & $\begin{array}{l}\text { Roke } \\
(1707)\end{array}$ & 10:00 19:00, July 23, 2017 & $\begin{array}{l}\text { LG, BY, NH, NX, } \\
\text { LC, HD, YD, GZ }\end{array}$ & 1592 \\
\hline & $\begin{array}{l}\text { Hato } \\
\text { (1713) }\end{array}$ & 5:00 17:00, August 23, 2017 & $\begin{array}{l}\text { LG, BY, NH, NX, PY, } \\
\text { RH, LC, HD, YD, GZ }\end{array}$ & 3370 \\
\hline \multirow{4}{*}{ Squall line } & $\begin{array}{l}\text { Pakhar } \\
\text { (1714) }\end{array}$ & 0:00 14:00, August 27, 2017 & $\begin{array}{l}\text { LG, BY, NH, NX, PY, } \\
\text { RH, LC, HD, YD, GZ }\end{array}$ & 5193 \\
\hline & 20160413 & 1:00 12:00, April 13, 2016 & $\begin{array}{l}\text { LG, BY, NH, NX, } \\
\text { PY, RH, HD, GZ }\end{array}$ & 767 \\
\hline & 20160417 & 17:00, April 17, 2016 4:00, April 18, 2016 & LG, NX, LC, GZ & 496 \\
\hline & 20170421 & 10:00 20:00, April 21, 2016 & $\begin{array}{l}\text { LG, BY, NH, NX, } \\
\text { PY, RH, TD }\end{array}$ & 1322 \\
\hline
\end{tabular}

The $N(D)\left(\mathrm{m}^{-3} \mathrm{~mm}^{-1}\right)$ at a discrete instant of time was calculated from the Parsivel2 and LPA10 disdrometers using the following equation:

$$
N\left(D_{i}\right)=\sum_{j=1}^{32} \frac{A_{i j}}{V_{j} T S \Delta D_{i}}
$$

where $A_{i j}$ is the number of drops determined in the size bin $i$ and velocity bin $j, V_{j}\left(\mathrm{~m} \mathrm{~s}^{-1}\right)$ is the fall speed for the velocity bin $j, T(\mathrm{~s})$ and $S\left(\mathrm{~m}^{2}\right)$ are the sampling time $(60 \mathrm{~s})$ and area $\left(0.0054 \mathrm{~m}^{2}\right.$ for Parsivel2 and $0.0063 \mathrm{~m}^{2}$ for LPA10), $D_{i}$ is the drop diameter for the size bin $i$, and $\Delta D_{i}$ is the corresponding diameter interval $(\mathrm{mm})$. The rainfall rate $R\left(\mathrm{~mm} \mathrm{~h}^{-1}\right)$ can also be calculated as follows:

$$
R=\frac{6 \pi}{10^{4}} \sum_{i=1}^{32 / 64} \sum_{j=1}^{32} N\left(D_{i}\right) D_{i}^{3} V_{j} \Delta D_{i}
$$

The equation for calculating the total concentration of raindrops $\mathrm{N}_{t}\left(\mathrm{~m}^{-3}\right)$ is

$$
N_{t}=\sum_{j=1}^{32 / 64} N\left(D_{i}\right) \Delta D_{i}
$$

Three-parameter gamma distribution [47] was used for DSD fitting. The equation is expressed as

$$
N(D)=N_{0} D^{\mu} \exp (-\lambda D)
$$

where $D(\mathrm{~mm})$ is the equivalent diameter, $N(D)\left(\mathrm{m}^{-3} \mathrm{~mm}^{-1}\right)$ is the number concentration of raindrop per unit volume unit size bin, $N_{0}\left(\mathrm{~mm}^{-(1+\mu)} \mathrm{m}^{-3}\right)$ is the intercept parameter, $\mu$ is the shape factor (dimensionless parameter), and $\lambda\left(\mathrm{mm}^{-1}\right)$ is the slope parameter. The $n$ th-order moment of the DSD is expressed as

$$
M_{n}=\sum_{D_{\min }}^{D_{\max }} N(D) D^{n} \Delta D
$$

The mass-weight mean diameter $\left(D_{\mathrm{m}}\right)$ is computed as the ratio of the fourth to the third moment of the size distribution

$$
D_{m}=\frac{M_{4}}{M_{3}} .
$$

The normalized intercept parameter $N_{\mathrm{w}}\left(\mathrm{m}^{-3} \mathrm{~mm}^{-1}\right)[43,48]$ is computed as

$$
N_{W}=\frac{(4.0)^{4}}{\pi \rho_{w}}\left(\frac{10^{3} W}{D_{m}^{4}}\right)
$$


where $\rho_{\mathrm{w}}$ is the density of water (assumed as $\left.1.0 \mathrm{gcm}^{-3}\right)$. W is the liquid water content $\left(\mathrm{g} / \mathrm{m}^{3}\right)$, which is computed as

$$
W=\frac{\pi}{6000} \sum_{i=1}^{64} N\left(D_{i}\right) D_{i}^{3} \Delta D_{i}
$$

\subsection{Retrieval of Dual-Pol Radar Variables from DSD}

Many algorithms are available for scattering by using non-spherical particles of heterogeneous media. In this paper, the backscattered and forward-scattered cross section of raindrops with various diameters are computed by applying the extended boundary condition method proposed by Barber et al. [49], and the raindrop ellipticity is calculated by using the method proposed by Pruppacher and Beard [50]. The scattering method was used by Liping Liu et al. [33] to investigate C-band dual-pol precipitation estimation. Reflectivity for horizontal and vertical polarimetrics $Z_{h, v}$ $\left(\mathrm{mm}^{-6} \mathrm{~m}^{-3}\right)$, the differential reflectivity factor $\left(Z_{\mathrm{dr}}\right.$ and $\left.Z_{\mathrm{DR}} ; \mathrm{dB}\right)$ and the specific differential phase $K_{\mathrm{DP}}\left({ }^{\circ} \mathrm{km}^{-1}\right)$ can be expressed as

$$
\begin{gathered}
Z_{\mathrm{h}, \mathrm{v}}=\frac{4 \lambda^{4}}{\pi^{4}\left|K_{w}\right|^{2}} \int_{D_{\min }}^{D_{\max }}\left|f_{\mathrm{hh}, \mathrm{vv}}(\pi, D)\right|^{2} N(D) d D, \\
Z_{D R}=10 \log _{10} \frac{Z_{\mathrm{h}}}{Z_{\mathrm{v}}}=10 \log _{10} Z_{d r}, \\
K_{D \mathrm{P}}=10^{-3} \frac{180}{\pi} \lambda \operatorname{Re}\left\{\int_{D_{\min }}^{D_{\max }}\left[f_{\mathrm{hh}}(0, D)-f_{\mathrm{vv}}(0, D)\right] N(D) d D\right\},
\end{gathered}
$$

where $\lambda(\mathrm{mm})$ is the radar wavelength; $D(\mathrm{~mm})$ is the equivalent diameter; $N(D)\left(\mathrm{m}^{-3} \mathrm{~mm}^{-1}\right)$ is the number concentration of raindrops in a unit volume of air and in the unit size interval; $D_{\min }$ and $D_{\max }$ are the minimum and maximum drop diameter of the actual DSD, respectively; $K_{w}$ is the dielectric constant factor of water; and $f_{\mathrm{hh}, \mathrm{vv}}(\pi, D)(\mathrm{mm})$ is the backscattering amplitude at the horizontal or vertical polarimetric. The horizontal equivalent reflectivity factor (i.e., $Z_{\mathrm{H}}$ ) represented in decibels is $Z_{\mathrm{H}}=10 \log _{10} Z_{\mathrm{h}}(\mathrm{dBZ}), Z_{\mathrm{v}}$ is the vertical equivalent reflectivity factor. Re refers to the real part of the integral, and $f_{\mathrm{hh}}(0, D)$ and $f_{\mathrm{vv}}(0, D)(\mathrm{mm})$ are the forward-scattering amplitudes at the horizontal and vertical polarimetrics, respectively.

\subsection{Method Fitting for QPE}

A basic conventional radar rainfall estimator $(Z-R)$ and polarimetric rainfall estimators with different combinations of radar variables, $R\left(K_{\mathrm{DP}}\right), R\left(Z_{\mathrm{h}}, Z_{\mathrm{DR}}\right)$, and $R\left(K_{\mathrm{DP}}, Z_{\mathrm{DR}}\right)$, are chosen for this study $[33,51,52]$. They are computed as

$$
\begin{gathered}
R_{1}\left(Z_{\mathrm{h}}\right)=a Z_{\mathrm{H}}^{b}, \\
R_{2}\left(K_{\mathrm{DP}}\right)=a\left(K_{\mathrm{DP}}\right)^{b}, \\
R_{3}\left(Z_{\mathrm{h}}, Z_{\mathrm{DR}}\right)=a Z_{\mathrm{H}}^{b} 10^{C Z_{D R},} \\
R_{4}\left(K_{D P}, Z_{\mathrm{DR}}\right)=a K_{D P}^{b} 10^{C Z_{D R},}
\end{gathered}
$$

where $R$ is in $\mathrm{mm} / \mathrm{h}, \mathrm{Z}_{\mathrm{H}}$ is in $\mathrm{mm}^{6} \mathrm{~m}^{-3}, \mathrm{Z}_{\mathrm{DR}}$ is in $\mathrm{dB}$, and $K_{\mathrm{DP}}$ is in ${ }^{\circ} / \mathrm{km}$.

(1) Conventional Fitting Method

In the conventional fitting method (CFM), all the DSD data are used for fitting a single rainfall estimator, such as $R\left(Z_{\mathrm{H}}, Z_{\mathrm{DR}}\right), R\left(K_{\mathrm{DP}}, Z_{\mathrm{DR}}\right)$, or $R\left(K_{\mathrm{DP}}\right)$. Each single estimator contains the information from all the DSD data.

In previous studies [14,53-55], $Z_{\mathrm{DR}}$ and $K_{\mathrm{DP}}$ are close to zero and exhibit high noise levels for light rainfall [56], and substantial observation error of $Z_{\mathrm{DR}}$ with low signal-noise-ratios (SNRs) leads to large estimation biases [33]. $Z_{\mathrm{h}}$ and $Z_{\mathrm{DR}}$ suffer from great attenuation with heavy precipitation, which 
leads to large biases. So $R\left(Z_{\mathrm{h}}, Z_{\mathrm{DR}}\right), R\left(K_{\mathrm{DP}}, Z_{\mathrm{DR}}\right)$, and $R\left(K_{\mathrm{DP}}\right)$ are used for fitting when rainfall is light $(R<6 \mathrm{~mm} / \mathrm{h})$, moderate $(6 \mathrm{~mm} / \mathrm{h}<R<50 \mathrm{~mm} / \mathrm{h})$, or heavy $(R>50 \mathrm{~mm} / \mathrm{h})$ [15], respectively.

(2) Piecewise Fitting Method

In this study, a new PFM for rainfall estimator based on a DSD dataset is used [57]. The core of the PFM is that the characteristics of the data for fitting an estimator should be consistent with those of the data for estimating precipitation with the use of the estimator. The characteristic is the rain rate in this study and when $R<6 \mathrm{~mm} / \mathrm{h}, 6 \mathrm{~mm} / \mathrm{h}<R<50 \mathrm{~mm} / \mathrm{h}$ and $R>50 \mathrm{~mm} / \mathrm{h}, R\left(Z_{\mathrm{h}}, Z_{\mathrm{DR}}\right), R\left(K_{\mathrm{DP}}, Z_{\mathrm{DR}}\right)$, and $R\left(K_{\mathrm{DP}}\right)$ are used to estimate precipitation, respectively. In this method, DSD data are divided into three parts according to the corresponding rain rate. The rainfall rates for the first part of the DSD data are less than $6 \mathrm{~mm} / \mathrm{h}$, those for the second part are between $6 \mathrm{~mm} / \mathrm{h}$ and $50 \mathrm{~mm} / \mathrm{h}$, and those for the third part are heavier than $50 \mathrm{~mm} / \mathrm{h}$. The three parts of the DSD data are used to fit $R\left(Z_{\mathrm{h}}, Z_{\mathrm{DR}}\right), R\left(K_{\mathrm{DP}}\right.$, $\left.Z_{\mathrm{DR}}\right)$, and $R\left(K_{\mathrm{DP}}\right)$, respectively. In addition, $R\left(Z_{\mathrm{h}}\right)$ is calculated to determine which estimator will be used to estimate precipitation. All the DSD data are used for $R\left(Z_{\mathrm{h}}\right)$ fitting, and $R\left(Z_{\mathrm{h}}\right)$ is used for all data. Although the intervals of rain rates for fitting are fixed, the $R\left(Z_{h}\right)$ fitted from the DSD varies with the precipitation type. To consider the effects of microphysical properties, the intervals of $Z_{\mathrm{h}}$ used are different for the two precipitation types in QPE.

\subsection{Parameters for Evaluating the Performance of QPE}

To evaluate the performance of QPE, the rainfall intensity $\left(R_{i}^{D S D}\right)$ derived from DSD data is set as the standard. Correlation coefficient (CC), root mean square error (RMSE), normalized error (NE), and normalized relative error (NB) are selected as the evaluation indicators, which can be computed as

$$
\begin{gathered}
C C=\frac{\sum_{i=1}^{n}\left(R_{i}^{C A L}-\overline{R_{i}^{C A L}}\right)\left(R_{i}^{D S D}-\overline{R_{i}^{D S D}}\right)}{\sqrt{\sum_{i=1}^{n}\left(R_{i}^{C A L}-\overline{R_{i}^{C A L}}\right) \sum_{i=1}^{n}\left(R_{i}^{D S D}-\overline{R_{i}^{D S D}}\right)^{2}}} \\
R M S E=\sqrt{\frac{\sum_{i=1}^{n}\left(R_{i}^{C A L}-R_{i}^{D S D}\right)^{2}}{n}} \\
N E=\frac{\sum_{1=1}^{n}\left|R_{i}^{C A L}-R_{i}^{D S D}\right|}{\sum_{i=1}^{n} R_{i}^{D S D}} \times 100 \\
N B=\frac{\sum_{1=1}^{n}\left(R_{i}^{C A L}-R_{i}^{D S D}\right)}{\sum_{i=1}^{n} R_{i}^{D S D}} \times 100
\end{gathered}
$$

where $R_{i}^{C A L}$ represents the calculated rainfall intensity using Equations (12)-(15), $R_{i}^{D S D}$ represents the calculated rainfall intensity using Equation (2) based on the DSD data, as the assessment criteria, the bar above the variables denotes the mean, and $\mathrm{n}$ is the number of samples for the evaluation.

\section{Characteristics of DSD and Polarimetric Variables for Typhoon and Squall Line}

\subsection{Comparison of DSD from Typhoon and Squall Line}

The microphysical parameters for two types of precipitation are computed, including $N(D)$ $\left(\mathrm{m}^{-3} \mathrm{~mm}^{-1}\right), \log 10 N_{w}$ (which indicates the raindrop concentration), $N_{t}, D$, and $D_{m}$, by using corresponding equations. The averaged DSD for typhoon and squall line are shown in Figure 2a. When $D<1 \mathrm{~mm}$, the trends of the averaged number concentration of typhoon and squall line particles are almost the same, although the $\log 10 N_{w}$ of typhoon is slightly higher. When $1 \mathrm{~mm}<D<3 \mathrm{~mm}$, the slope of the averaged number concentration of typhoon precipitation is considerably larger than that of the squall line. The $\log 10 N_{w}$ of typhoon is larger than that of the squall line when $1.5 \mathrm{~mm}<D<$ $3 \mathrm{~mm}$. When $3 \mathrm{~mm}<D<5 \mathrm{~mm}$, the $\log 10 N_{w}$ of typhoon particles is considerably smaller than the squall line. The primary difference of DSD from typhoon and squall line precipitation lies in that the 
former has more small particles, fewer large particles, whereas the opposite condition is observed in the latter.

Figure $2 \mathrm{~b}$ shows the scatterplot of $\log 10 N_{w}$ versus $D_{m}$ for typhoon and squall line. The two gray rectangles correspond to the maritime and continental convective clusters reported by Bringi et al. [43]. The typhoon rain is mostly plotted in the upper left of the red dashed line (i.e., $D_{m} \approx 0.75-2.0 \mathrm{~mm}$ and $\log 10 N_{w} \approx 3.75-4.4$ ), while squall line rain is below the red dashed line. When $0.75 \mathrm{~mm}<D_{m}$ $<2.0 \mathrm{~mm}$, the concentration of raindrops for typhoon is higher than that of the squall line, with the highest reaching up to $5.0\left(\log 10 N_{w} \approx 5.0\right)$. The typhoon rain is mostly plotted over the "maritime-like" cluster. Although points of typhoon and squall line rainfall appear in the "continental cluster", which are relatively fewer, the DSDs of this typhoon rain have a relatively high number concentration and a small average diameter; the opposite condition is observed in the DSDs of the squall line rain. The corresponding DSDs of this typhoon and squall line rain have a higher number concentration of raindrops with small diameters, compared with the results from Bringi et al. [43]. No remarkable difference is observed in the particle number of typhoon and squall line precipitation on the two sides of the orange dashed line. Thus, both convective and stratiform rain are commonly present in the typhoon and squall line. The convective and stratiform precipitation of the two systems should be studied further in the future.

Figure 2c,d show the scatterplot of $\log 10 N_{t}$ versus $D$ with different rainfall rates for typhoon and squall line. When $R<5 \mathrm{~mm} / \mathrm{h}$, the DSDs of typhoon rain are even, whereas those of squall line rain are more centered. When $5 \mathrm{~mm} / \mathrm{h} \leq R<10 \mathrm{~mm} / \mathrm{h}$ for the DSDs of squall line rain, the range of diameter is relatively wider, and the range of number concentration is slightly lower. When $50 \mathrm{~mm} / \mathrm{h} \leq R<70 \mathrm{~mm} / \mathrm{h}$, the corresponding DSDs of typhoon rain are primarily within the area of $D \approx 1.0-2.0 \mathrm{~mm}$ and $\log 10 N_{t} \approx 2.8-3.7$; while the DSDs of squall line rain are primarily within the area of $D \approx 1.0-1.5 \mathrm{~mm}$ and $\log 10 N_{t} \approx 3.0-3.6$. For the DSDs of typhoon rain, the range of diameter is relatively wider and the range of number concentration is slightly higher. The $\log 10 N_{t}$ of typhoon rain increases faster than that of squall line with $D$ at a corresponding rainfall intensity. For heavy rainfall intensity $(R \geq 50 \mathrm{~mm} / \mathrm{h})$, the mean diameter of typhoon raindrops is small but the concentration is high.

Figure 2e,f show the percentage contribution of various diameter raindrops to $N_{t}$ and $R$ for typhoon and squall line rainfall. For typhoon rain, while the values of $D$ are under $1 \mathrm{~mm}$, the contribution to the total raindrop number (about 63\%) is the highest, and when $1 \mathrm{~mm} \leq D<1.5 \mathrm{~mm}$, the contribution to the rainfall rate (about 64\%) is the highest. For squall line rainfall, when $1 \mathrm{~mm} \leq D<1.5 \mathrm{~mm}$, the contribution to the total raindrop number (about $56 \%$ ) and the rainfall rate (about 70\%) are both the highest. Evidently, the small raindrops of typhoon precipitation are greater than that of the squall line, which contribute more to the rainfall rate $(R)$. When $1 \mathrm{~mm} \leq D<1.5 \mathrm{~mm}$, the raindrops of squall line rain are more than those of the typhoon, thereby also contributing considerably to the rainfall rate $(R)$.

As a result, the corresponding DSDs of typhoon and squall line precipitation exhibit different characteristics. Typhoon and squall line rain are more likely tobe "maritime-like" cluster, which is a compound of convective and stratiform precipitation. 
(a)

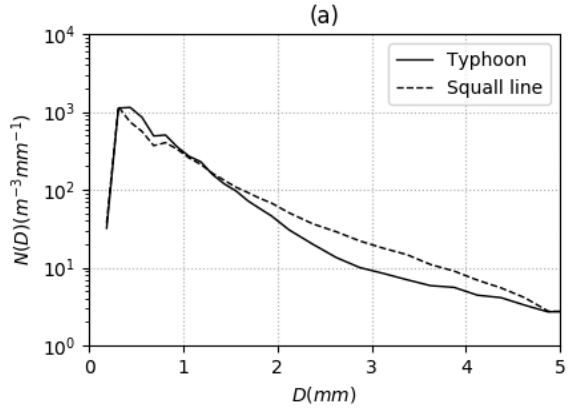

(c)

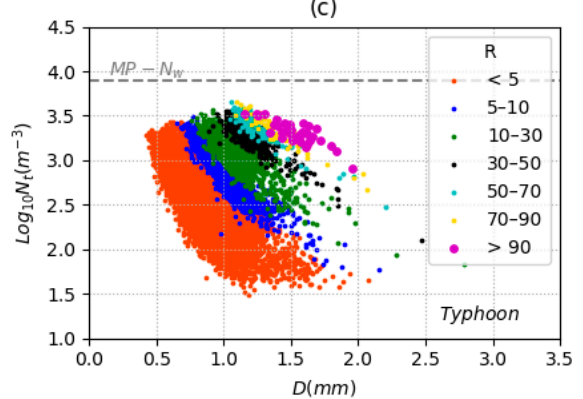

(e)

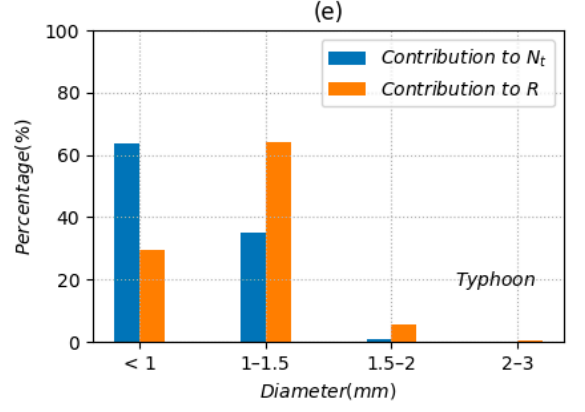

(b)

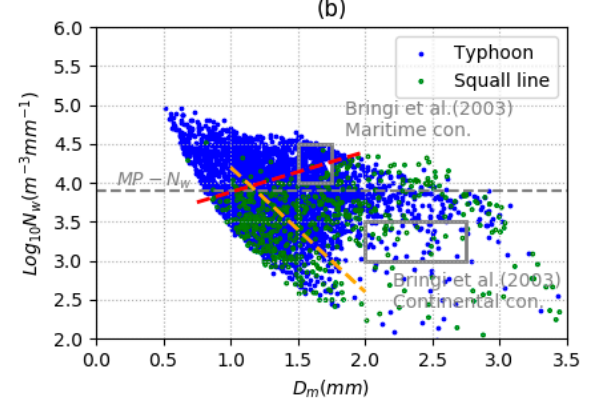

(d)

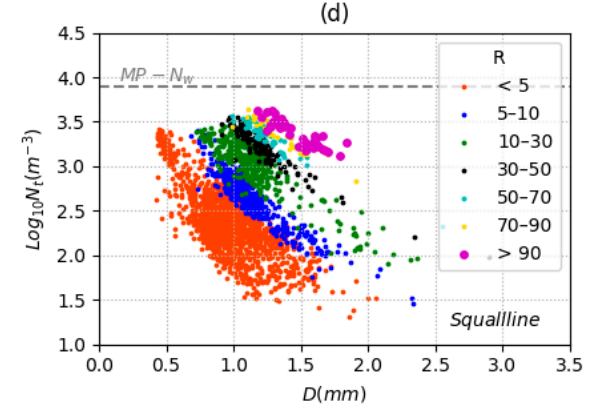

(f)

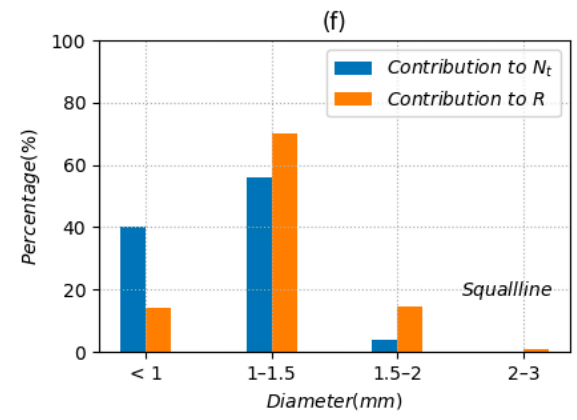

Figure 2. (a) The averaged DSD for typhoon and squall line. The solid line is for typhoons and dotted line is for squall lines. (b) The scatterplot of $\log 10 N_{\mathrm{w}}$ versus $D_{\mathrm{m}}$ for typhoon (solid blue dots) and squall line (blank green dots). The two gray rectangles correspond to the maritime and continental convective clusters reported by Bringi et al. [43]. The orange dashed line is that of Bringi et al. [43] for stratiform rain; the red dashed line is applied in this study to distinguish typhoon and squall line precipitation in southern China. (c,d) The scatterplot of $\log 10 N_{\mathrm{t}}$ versus $D$ with different rainfall rates for typhoon and squall line. (e,f) The percentage contribution of various diameter raindrop to $N_{\mathrm{t}}$ and $R$ for typhoon and squall line.

\subsection{Comparison of Polarimetric Radar Variables}

The S-band dual-pol radar variables $Z_{H}, Z_{D R}$, and $K_{D P}$ were computed using Equations (9)-(11) in Section 2.2, respectively. The occurrence frequencies of $Z_{D}$ and $K_{D P}$ with different $Z_{\mathrm{H}}$ are calculated. Their mean and standard deviation are also calculated (Figure 3).

Figure $3 a, b$ show that the maximum $Z_{H}$ of the typhoon is about $3.5 \mathrm{dBZ}$ smaller than that of the squall line, and the maximum $Z_{D R}$ is about $1.05 \mathrm{~dB}$ smaller. $Z_{D R}$ of the typhoon precipitation changes gradually with $Z_{H}$ (smaller slope), while the $Z_{H}$ of the squall line rain is relatively strong with more data over $45 \mathrm{dBZ}$ (larger slope), which is due to the fact that the DSDs of typhoon rain have a higher proportion of small drops than the squall line does.

Figure $3 c, d$ show that the maximum $Z_{H}$ of the typhoon rainfall is smaller by about $2 \mathrm{dBZ}$ than that of the squall line, and the maximum $K_{D P}$ is smaller by about $1.55^{\circ} / \mathrm{km}$. $K_{D P}$ changes with $Z_{H}$ similarly (small differences in the slope) for the typhoon and squall line precipitation. This result indicates few differences of $K_{D P}$ from typhoon and squall line rain at the same $Z_{H}$. The typhoon rainfall has a smaller proportion of raindrops with large sizes than the squall line does. 
(a)

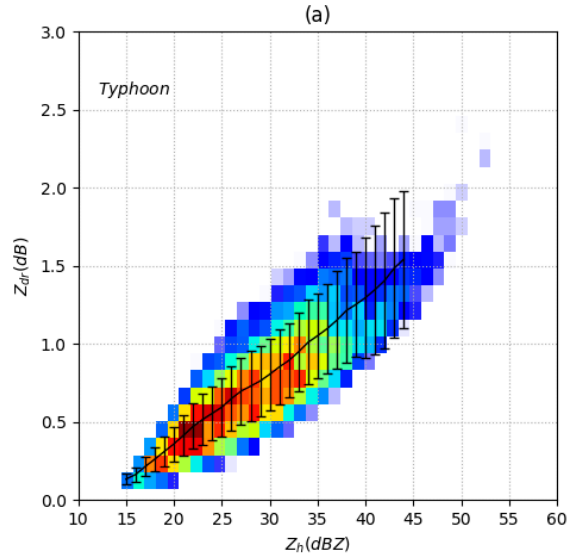

(c)

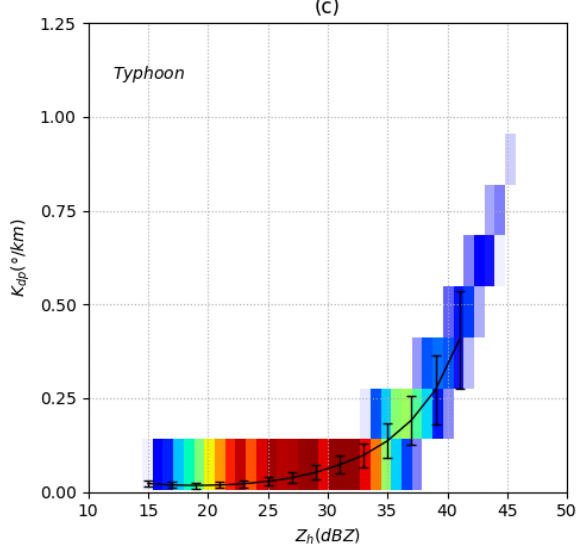

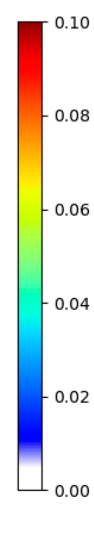

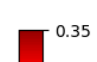

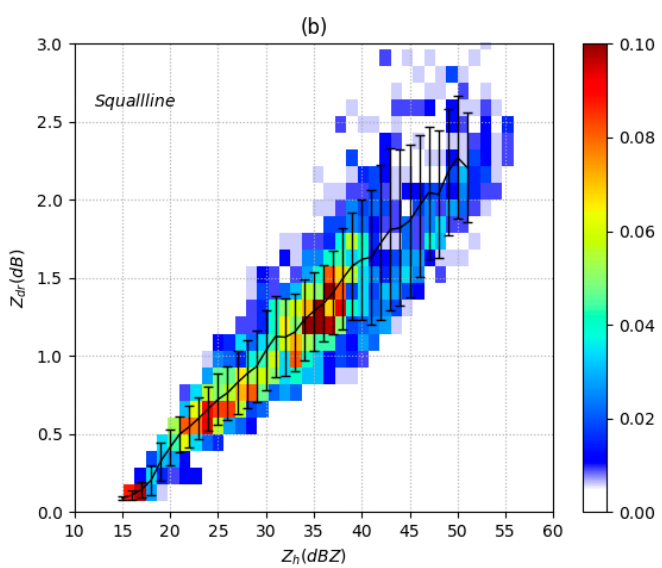

(d)

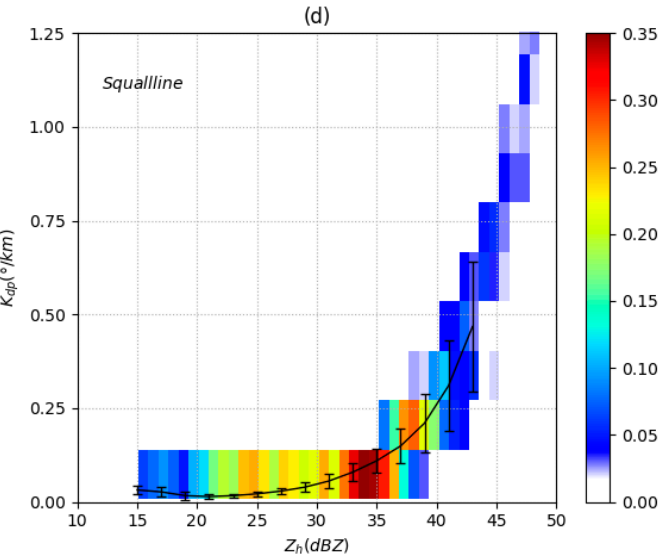

Figure 3. The averaged $Z_{\mathrm{DR}}, K_{\mathrm{DP}}$, and occurrence frequencies of $Z_{\mathrm{DR}}$ and $K_{\mathrm{DP}}$ for two precipitation systems. (a,d) for typhoon, $(\mathbf{b}, \mathbf{d})$ for squall line. The colorbar stands for occurrence frequencies of $Z_{\mathrm{DR}}$ and $K_{\mathrm{DP}}$, and the black lines and vertical black lines indicate the mean and variance of $Z_{\mathrm{DR}}$ or $K_{\mathrm{DP}}$, respectively.

To summarize, the different DSDs of the two precipitation types lead to different characteristics of polarimetric radar variables. Particularly for the precipitation that has different $Z_{H}$ and their $Z_{D R}$, $K_{D P}$ and the occurrence frequency of $Z_{D R}$ and $K_{D P}$ are all different. Thus, for radar QPE, different estimators should be developed for different precipitation systems and regions.

\section{Dual-Pol Estimators for Typhoon and Squall Line}

\subsection{Comparison of the Parameters for the Two Estimators}

\subsubsection{Estimators and Their Performance from CFM}

Nonlinear fitting is employed to fit Equations (12)-(15) for typhoon and squall line. The estimators from CFM are shown in Table 3, and a, b, and c are the coefficients of the Equations (12)-(15). The rainfall rate by disdrometer are considered "real" to evaluate the fitting results for each estimator, and the results are shown in Table 4. 
Table 3. List of coefficients for the estimators from CFM.

\begin{tabular}{ccccc}
\hline Precipitation System & Estimator & $\mathbf{a}$ & $\mathbf{b}$ & $\mathbf{c}$ \\
\hline \multirow{4}{*}{ Typhoons } & $R 1\left(Z_{H}\right)$ & 0.060 & 0.587 & $\mathrm{X}$ \\
& $R 2\left(K_{D P}\right)$ & 33.614 & 0.833 & $\mathrm{X}$ \\
& $R 3\left(Z_{H}, Z_{D R}\right)$ & 0.012 & 0.882 & -0.358 \\
& $R 4\left(K_{D P}, Z_{D R}\right)$ & 52.801 & 0.957 & -0.113 \\
\hline \multirow{5}{*}{ Squall lines } & $R 1\left(Z_{H}\right)$ & 0.020 & 0.677 & $\mathrm{X}$ \\
& $R 2\left(K_{D P}\right)$ & 32.023 & 0.881 & $\mathrm{X}$ \\
& $R 3\left(Z_{H}, Z_{D R}\right)$ & 0.007 & 0.947 & -0.409 \\
& $R 4\left(K_{D P}, Z_{D R}\right)$ & 61.027 & 0.983 & -0.146 \\
\hline
\end{tabular}

Table 4. The performance for the estimators from CFM.

\begin{tabular}{cccccc}
\hline Precipitation System & Estimator & CC & RMSE (mm/h) & NE (\%) & NB (\%) \\
\hline \multirow{5}{*}{ Typhoons } & $R 1\left(Z_{H}\right)$ & 0.952 & 3.564 & 27.37 & 3.65 \\
& $R 2\left(K_{D P}\right)$ & 0.990 & 1.622 & 12.36 & 2.65 \\
& $R 3\left(Z_{H}, Z_{D R}\right)$ & 0.992 & 1.505 & 12.78 & -2.49 \\
& $R 4\left(K_{D P}, Z_{D R}\right)$ & 0.996 & 1.043 & 7.75 & 0.08 \\
\hline \multirow{5}{*}{ Squall lines } & $R 1\left(Z_{H}\right)$ & 0.943 & 6.621 & 27.00 & 0.97 \\
& $R 2\left(K_{D P}\right)$ & 0.988 & 3.139 & 11.60 & 0.81 \\
& $R 3\left(Z_{H}, Z_{D R}\right)$ & 0.995 & 2.030 & 8.78 & -0.75 \\
& $R 4\left(K_{D P}, Z_{D R}\right)$ & 0.996 & 1.823 & 6.66 & 0.59 \\
\hline
\end{tabular}

The same data are used to fit the four estimators for the two precipitation types. This approach makes analyzing the characters of the four estimators and comparing the performances of these estimators and their suitability more convenient. Table 4 shows that the performances of the four estimators follow the order of $R 1\left(Z_{H}\right)<R 2\left(K_{D P}\right)<R 3\left(Z_{H}, Z_{D P}\right)<R 4\left(K_{D P}, Z_{D R}\right)$ for typhoon and squall line. However, $R 3\left(Z_{H}, Z_{D P}\right)$ is underestimated, whereas the other three are overestimated. The performance of $R 1\left(Z_{H}\right)$ is the worst because only one variable $Z_{H}$ is used and $Z_{H}$ fluctuated greatly with the DSDs $[36,46]$. The performance of $R 2\left(K_{D P}\right)$ is better than that of $R 1\left(Z_{H}\right)$, which can be attributed to the fact that the exponent of $K_{D P}$ is closer to 1 than that of $Z_{H}$. The correlation between $K_{D P}$ and $R$ is more linear, which means that $K_{D P}$ can better adapt to the changes of the DSDs. $R 3\left(Z_{H}\right.$, $\left.Z_{D P}\right)$ produced better results than both $R 1\left(Z_{H}\right)$ and $R 2\left(K_{D P}\right)$ due to the introduction of two parameters, namely, $Z_{H}$ and $Z_{D R}$, which added more information of raindrop diameters and reduced the impact of the DSDs' variability. $R 4\left(K_{D P}, Z_{D R}\right)$ had the optimal performance, taking advantage of $K_{D P}$, which can adapt to the DSDs' variability and also includes the information of raindrop diameters represented by $Z_{D R}$.

The assessment results of estimators from CFM are as follows: $R 1\left(Z_{H}\right)$ produced the smallest value for CC, the largest values for RMSE and NE, and the largest absolute value for NB, and the performance was the worst. $R 4\left(K_{D P}, Z_{D R}\right)$ generated the best performance with the largest $C C$, the smallest RMSE and NE, and the smallest absolute NB.

\subsubsection{Estimators and Their Performance from PFM}

Although the analysis in Section 4.1.1 showed that $R 4\left(K_{D P}, Z_{D R}\right)$ produced the best results, the evaluation is performed using a single estimator under the ideal conditions that the radar observations are accurate. In the practical application of QPE, the quality of the dual-pol radar observations should be fully considered. Many factors, such as the quality of the radar signals and the characteristics of the precipitation, affect the quality of the polarimetric radar observations. With different rainfall rates, different variables of polarimetric radar observation should be employed for QPE. In general, dual-polarimetric radar rainfall retrievals rely on the presence of larger drops as these are non-spherical and produce different responses for the horizontal and vertical polarimetrics. In light rain there are usually only a small number of large, non-spherical drops so the dual-pol signals are not reliable. Heavy rain is usually accompanied by hail, which can further impact the quality of 
$Z_{\mathrm{H}}$ and $Z_{\mathrm{DR}}$ observations. However, the estimated value of $K_{\mathrm{DP}}$ can remain accurate because it has the advantage of not being affected by the absolute calibration error and the attenuation, even though spherical hail is present for s-band dual-pol radar.

Given the above characteristics of the polarimetric radar observation, different estimators should be selected in the practical application of QPE according to the quality of the radar signals and the rainfall intensity. The scheme can be described as follows: only the estimator in the form of $Z_{\mathrm{H}}$ is applied for light rain; when the rain is light but the radar signals are reliable, an estimator in the form of $Z_{\mathrm{H}}$ and $Z_{\mathrm{DR}}$ can be used; when the rain is moderate, the quality of the radar polarimetric observation variables is the best, and an estimator in the form of $Z_{\mathrm{DR}}$ and $K_{\mathrm{DP}}$ should be selected; and only the estimator in the form of $K_{\mathrm{DP}}$ should be applied to estimate heavy rain.

On the basis of the nonlinear method, the Equations (12)-(15) are fitted using the PFM with the DSD data from typhoon and squall line precipitation, and their coefficients are summarized in Table 5, and $a, b$, and $c$ are the coefficients of the Equations (12)-(15).

Table 5. List of coefficients for the estimators from PFM.

\begin{tabular}{ccccc}
\hline Precipitation Type & Estimator & $\mathbf{a}$ & $\mathbf{b}$ & $\mathbf{c}$ \\
\hline \multirow{4}{*}{ Typhoon } & $R 1\left(Z_{H}\right)$ & 0.060 & 0.587 & $\mathrm{X}$ \\
& $R 2\left(K_{D P}\right)$ & 36.776 & 0.752 & $\mathrm{X}$ \\
& $R 3\left(Z_{H}, Z_{D R}\right)$ & 0.0253 & 0.842 & -0.578 \\
& $R 4\left(K_{D P}, Z_{D R}\right)$ & 52.778 & 0.929 & -0.117 \\
\hline \multirow{5}{*}{ Squall line } & $R 1\left(Z_{H}\right)$ & 0.020 & 0.677 & $\mathrm{X}$ \\
& $R 2\left(K_{D P}\right)$ & 36.260 & 0.788 & $\mathrm{X}$ \\
& $R 3\left(Z_{H}, Z_{D R}\right)$ & 0.018 & 0.837 & -0.433 \\
& $R 4\left(K_{D P}, Z_{D R}\right)$ & 55.773 & 0.940 & -0.130 \\
\hline
\end{tabular}

An analysis of the data in Table 5 reveals great distinctions in the coefficients of typhoon and squall line precipitation for the same estimator. The values of coefficients ' $a$ ' for the $R 1\left(Z_{H}\right), R 2\left(K_{D P}\right)$, and $R 3\left(Z_{H}, Z_{D R}\right)$ for the typhoon precipitation are larger than those for the squall lines. However, the values of coefficients ' $a$ ' are smaller for typhoon than for squall line when the $R 4\left(K_{D P}, Z_{D R}\right)$ is applied. The characteristics of DSD determine the coefficients for the fitting estimator. Typhoon rain contains a small total concentration of raindrops and a low proportion of large raindrops; thus, the values of coefficients ' $a$ ' in $R 1\left(Z_{H}\right), R 2\left(K_{D P}\right)$, and $R 3\left(Z_{H}, Z_{D R}\right)$ relationships tend to be larger. Meanwhile, typhoon rain has a low proportion of large raindrops but a high number concentration of small raindrops, and the values of coefficient ' $a$ ' tend to be smaller in the $R 4\left(K_{D P}, Z_{D R}\right)$. This finding indicates that the number concentration of small raindrops has a more considerable impact on $R 4\left(K_{D P}\right.$, $Z_{D R}$ ) than the proportion of large raindrops does.

The coefficients of the estimators also show the influence level of the corresponding variables for the final results. In other words, larger absolute values of the coefficients of $Z_{H}, K_{D P}$, and $Z_{D R}$ in the estimators correspond to a considerable impact of the corresponding polarimetric radar variables on the estimated results $(R)$, which means that $R$ is more sensitive to this variable. We can easily see from Table 5 that typhoon rain has larger a1, a2 and smaller b1 and b2 than squall line does in $R=\mathrm{a} 1 \times Z_{D P}^{\mathrm{b} 1}$, $R=\mathrm{a} 2 \times K_{D P}^{\mathrm{b} 2}$ relationships.

Table 6 clearly shows notable differences in the results $(R)$ using CFM and PFM in $R 2\left(K_{D P}\right)$. For typhoon precipitation, when $K_{D P}$ is in the range of $0.5^{\circ}$ to $3^{\circ} / \mathrm{km}$, the estimated $R$ using PFM is higher by about $0.05-2.97 \mathrm{~mm} / \mathrm{h}$ than that using CFM. When $K_{D P}$ is within $3.5^{\circ}-4^{\circ} / \mathrm{km}$, the estimated $R$ using PFM is lower by about $1.12-2.39 \mathrm{~mm} / \mathrm{h}$ than that using CFM. For squall line precipitation, when $K_{D P}$ is within $0.5^{\circ}-3.5^{\circ} / \mathrm{km}$, the estimated $R$ using PFM is higher by about $0.78-4.24 \mathrm{~mm} / \mathrm{h}$ than that using CFM. When $K_{D P}=4$, the estimated $R$ using PFM is lower by about $0.47 \mathrm{~mm} / \mathrm{h}$ than that using CFM. For both typhoon and squall line rain, the difference in the results obtained using the two methods increases first along with the increase in $K_{D P}$ and then decreases, and the estimated $R$ 
using PFM is higher than that using CFM. When radar observation $K_{D P}=1^{\circ} / \mathrm{km}$, the difference in the estimated results is the largest between that using PFM and CFM for the $R 2\left(K_{D P}\right)$ relationship.

Table 6. Comparison of the results using the two methods in $R 2\left(K_{\mathrm{DP}}\right)$.

\begin{tabular}{|c|c|c|c|c|}
\hline \multirow{2}{*}{$\begin{array}{c}K_{\mathrm{DP}} \\
\left({ }^{\circ} / \mathrm{km}\right)\end{array}$} & \multicolumn{2}{|c|}{ CFM } & \multicolumn{2}{|c|}{ PFM } \\
\hline & R_TY (mm/h) & R_SQ (mm/h) & R_TY (mm/h) & R_SQ (mm/h) \\
\hline 0.5 & 18.87 & 17.39 & 21.84 & 21.00 \\
\hline 1 & 33.61 & 32.02 & 36.78 & 36.26 \\
\hline 1.5 & 47.12 & 45.77 & 49.89 & 49.91 \\
\hline 2 & 59.89 & 58.97 & 61.93 & 62.61 \\
\hline 2.5 & 72.13 & 71.77 & 73.25 & 74.65 \\
\hline 3 & 83.96 & 84.28 & 84.01 & 86.18 \\
\hline 3.5 & 95.46 & 96.53 & 94.34 & 97.31 \\
\hline 4 & 106.70 & 108.58 & 104.31 & 108.11 \\
\hline
\end{tabular}

\subsection{Evaluation of the Performance of QPEs Obtained using CFM and PFM}

Estimators obtained using the CFM and PFM are evaluated. The rainfall intensity from the DSD is considered a "truth", and the calculated dual-pol variables from DSD are input to retrieve the rainfall rate. The average rainfall intensity from the DSD is considered a "standard value", and the indicators of CC, RMSE, NE, and NB (shown in Table 7) are used to evaluate the QPE performance. The CFM Average $R$ are calculated using the average of the sum of $R 2\left(K_{\mathrm{DP}}\right), R 3\left(Z_{\mathrm{H}}, Z_{\mathrm{DR}}\right)$, and $R 4\left(K_{\mathrm{DP}}, Z_{\mathrm{DR}}\right)$ in Table 3, and the PFM Average $R$ are calculated using the average of the sum of $R 2\left(K_{\mathrm{DP}}\right), R 3\left(Z_{\mathrm{H}}, Z_{\mathrm{DR}}\right)$, and $R 4\left(K_{\mathrm{DP}}, Z_{\mathrm{DR}}\right)$ in Table 5 , where $R 2\left(K_{\mathrm{DP}}\right), R 3\left(Z_{\mathrm{H}}, Z_{\mathrm{DR}}\right)$, and $R 4\left(K_{\mathrm{DP}}, Z_{\mathrm{DR}}\right)$ were calculated with corresponding rain rate of DSD data, which are less than $6 \mathrm{~mm} / \mathrm{h}$, between $6 \mathrm{~mm} / \mathrm{h}$ and $50 \mathrm{~mm} / \mathrm{h}$, and heavier than $50 \mathrm{~mm} / \mathrm{h}$, respectively. Results showed that average rainfall intensity estimated using PFM is higher by about $2.7 \%$ for typhoon precipitation than that using CFM and by about $1.1 \%$ for squall line.

Table 7 clearly shows that the average rainfall intensities estimated using PFM are closer or even equal to the standard value than those estimated using CFM. Thus, in terms of the average rainfall intensity, PFM gives better results than CFM. This finding can be attributed to the deviation of system and sampling for $Z_{D R}$ and $K_{D P}$ measurements in light rain. A comparison of the evaluation indicators of PFM and CFM clearly shows that the CC of the former is slightly larger and the RMSE is slightly lower. The NE is markedly smaller by at least 10.3\% than PFM. The NB indicates that it is underestimated for typhoon rain; it is overestimated using PFM but underestimated using CFM for squall line precipitation. The absolute values of NB for PFM evidently decrease and are at least $95.4 \%$ lower. A comprehensive assessment of the four indicators shows that PFM gives better estimation. Thus, in practical application, PFM should be selected, which can fit the estimators well according to the microphysical properties of precipitation and improve estimation accuracy.

Table 7. The performance of QPEs obtained by CFM and PFM.

\begin{tabular}{ccccccc}
\hline $\begin{array}{c}\text { Precipitation Type } \\
\text { (Standard Value) }\end{array}$ & $\begin{array}{c}\text { Fitting } \\
\text { Method }\end{array}$ & Average R & CC & $\begin{array}{c}\text { RMSE } \\
(\mathbf{m m} / \mathbf{h})\end{array}$ & NE (\%) & NB (\%) \\
\hline \multirow{2}{*}{ Typhoon (6.49) } & PFM & 6.49 & 0.994 & 1.227 & 8.39 & -0.006 \\
& CFM & 6.32 & 0.993 & 1.349 & 10.68 & -2.62 \\
\hline \multirow{2}{*}{ Squall Line (11.15) } & PFM & 11.15 & 0.991 & 2.608 & 8.25 & 0.050 \\
& CFM & 11.03 & 0.991 & 2.728 & 9.10 & -1.08 \\
\hline
\end{tabular}

\subsection{Sensitivity Experiment for Different QPE Estimators}

The considerable difference in DSD of the two precipitation types leads to the differences in the coefficients of the rainfall estimator. A sensitivity experiment was conducted to evaluate the effects of the estimators on QPE. In this experiment, the estimators for typhoon precipitation are used for squall line and the estimators for squall line rain are used for the typhoon. 
Figure 4 shows the cross-evaluation of the precipitation estimation performances for typhoon and squall line rain estimated by using PFM with the four estimators. The results are better for the corresponding type of precipitation. For PFM, the proportions of the sample number of DSDs used in the three estimators from the typhoon and the squall line followed the order of $R 2<R 4<R 3$. The percentage of sample number used in $R 3$ for typhoon rain is $74.1 \%$ and that for squall line is $63.8 \%$. The number of small raindrops is higher for typhoon than for squall line. When the estimators for squall line precipitation are used to estimate typhoon, $R 2$ and $R 4$ give a slight overestimation, whereas $R 3$ gives an underestimation that is not negligible. This result might be one of the factors that cause relatively major errors. When the estimators for typhoon rain are used to estimate squall line precipitation, $R 3$ and $R 4$ give a slight overestimation, whereas $R 2$ gives an underestimation that is not negligible, thereby providing another factor that causes errors.
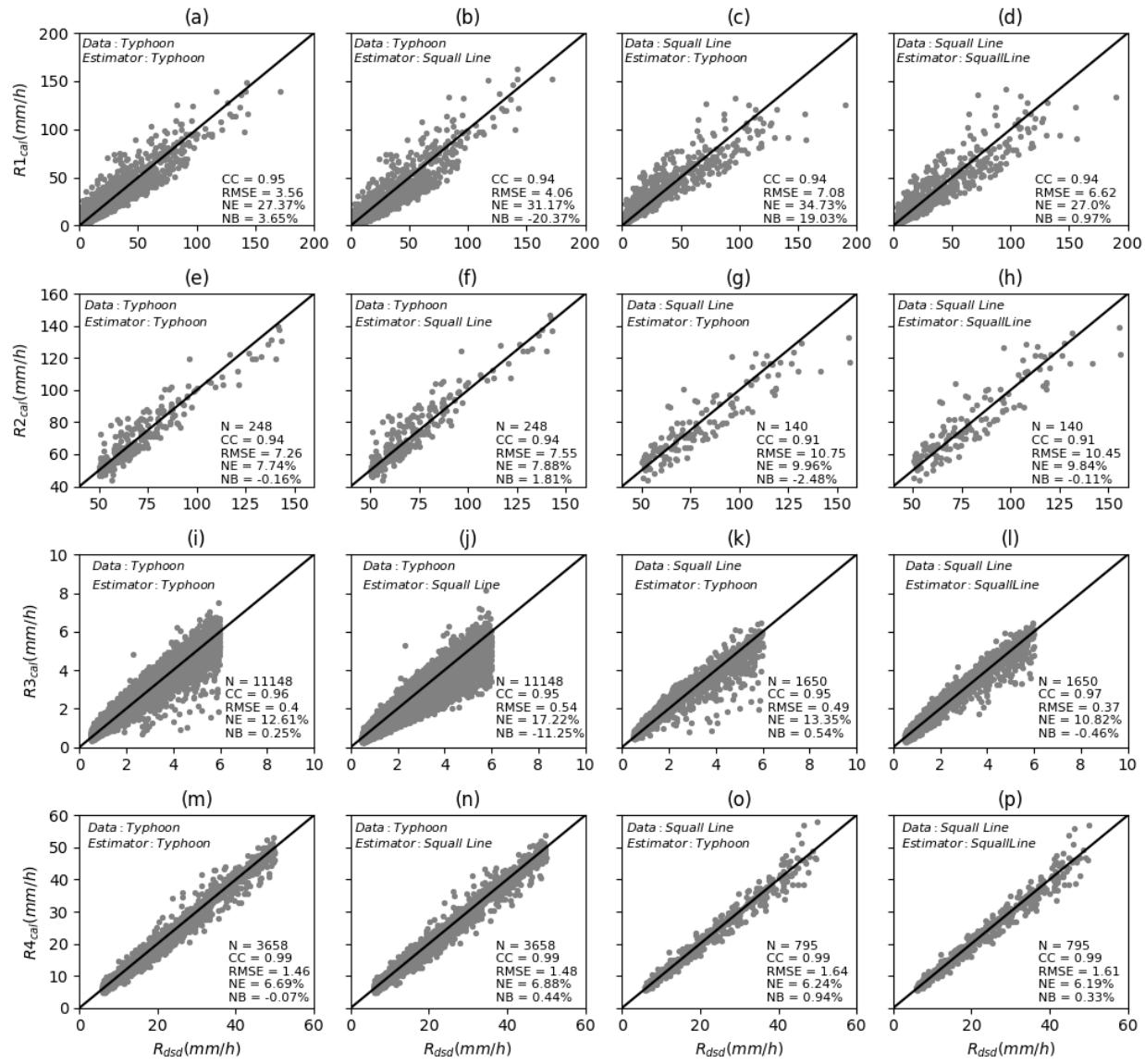

Figure 4. The scattering of retrieved rainfall rates from estimators using PFM and that from DSD. The x-axis $R_{\mathrm{dsd}}$ represents rainfall rates calculated directly from DSD data, and the y-axis $R n_{\text {cal }}$ represents the rainfall rates retrieved from four estimators for typhoon and squall line in Table 3 (where $R n$ corresponds to the estimators in Table 3, $R 1(\mathbf{a}-\mathbf{d}), R 2(\mathbf{e}-\mathbf{h}), R 3(\mathbf{i}-\mathbf{l})$, and $R 4(\mathbf{m}-\mathbf{p}))$. Adopted data, estimator, CC, RMSE, NE, and NB are also denoted in each panel.

Figure 5 shows the cross-evaluation of the precipitation estimation performances for typhoon and squall line, estimated using CFM and PFM, respectively. For typhoon and squall line precipitation, the results are better when the estimator that corresponds to the precipitation type is employed whether the estimators from CFM or PFM are selected. Whether CFM or PFM is used, when the estimators for squall line precipitation are used to estimate typhoon, the performance of the estimators decreases more notably than when the estimators of typhoon rainfall are used. When the estimators for typhoon precipitation are used to estimate squall line rain, the performance of the estimators decreases more slightly than when the estimators of squall line rainfall are used. The different DSDs from typhoon 
and squall line precipitation leads to the different estimators and further impacts the performance of rainfall estimation.

(a)

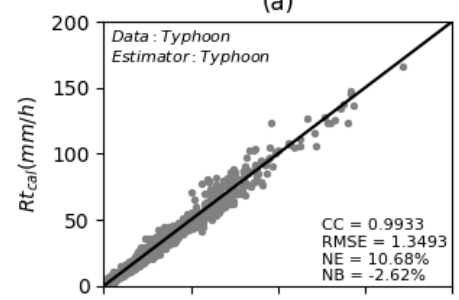

(c)

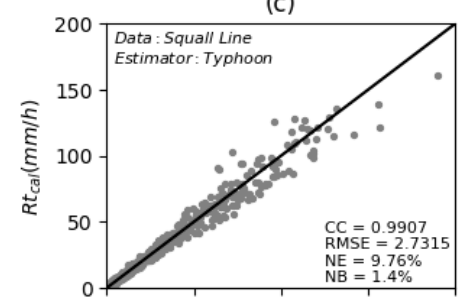

(e)

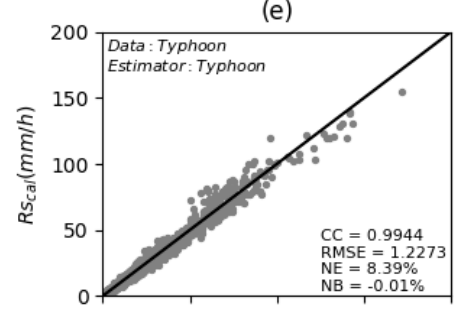

(g)

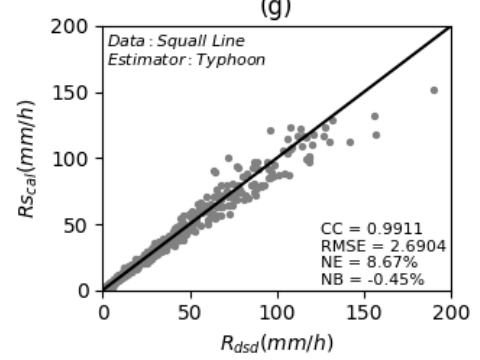

(b)

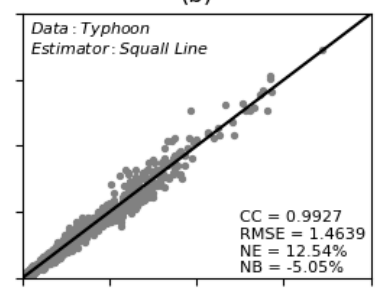

(d)

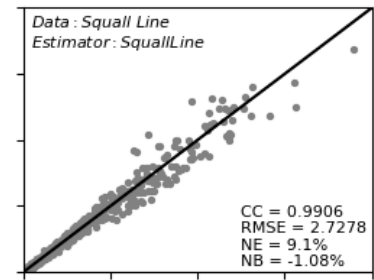

(f)

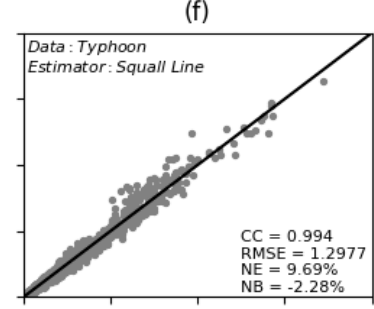

(h)

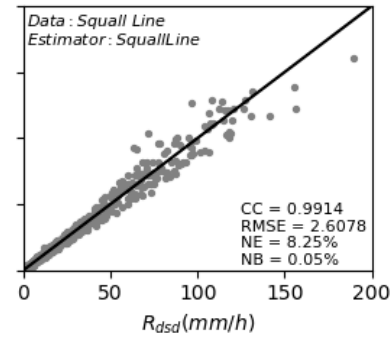

Figure 5. The scattering of retrieved rainfall rates from estimators using CFM or PFM and that from DSD. The x-axis $R_{\mathrm{dsd}}$ represents rainfall intensity calculated directly from DSD data, and the y-axis $R t_{\mathrm{cal}}$ (a-d) represents the rainfall rate calculated from CFM; the y-axis $R s_{\text {cal }}(\mathbf{e}-\mathbf{h})$ represents the rainfall rate calculated from PFM. Adopted data, estimator, CC, RMSE, NE, and NB are also denoted in each panel.

A comparison of the estimation performance of PFM and CFM shows that the estimators derived from PFM can produce better results for a specific precipitation type. The performance of QPE improved more noticeably for typhoon rainfall than for squall lines.

\section{Discussion and Conclusions}

\subsection{Discussion}

The DSD data collected with Parsivel2 and LPA10 disdrometers are used for this investigation. The observation principle of LPA10 is the same as that of a Parsivel2 disdrometer. It can be considered a Chinese version of OTT Parsivel, although the classification of diameters are slightly different (64 size bins for LAP10 and 32 size bins for Parsivel2). Whether this difference causes deviation needs further analysis.

The observed DSD data collected with the disdrometers is used as "truth" when the performances of estimators are evaluated in this study. The detection capability of dual-pol radar was not analyzed. 
In practice, the difference between the radar observation and the disdrometer can cause errors in terms of observation objects and values. This issue will be the main supplementary content for further research.

Moreover, the used QPE scheme for the typhoon and squall line rainfall showed advantages for only some cases. It needs to be validated by more general precipitation events.

\subsection{Conclusions}

On the basis of observations from the 10 disdrometers set up by the Guangdong Meteorological Bureau, the characteristics of derived radar polarimetric variables and the DSD were analyzed for two precipitation types in this study.

A set of QPE algorithms for S-band dual-pol radar was developed with the CFM and PFM for studying southern China's typhoon and squall line rainfall. The performance of the QPE algorithms was evaluated with rainfall rate and dual-pol variables from DSD. The following conclusions can be drawn:

(1) The DSD in typhoon and squall line precipitation exhibits certain distinctions. Typhoon precipitation contains more small raindrops. The majority of the raindrops are at $D<1 \mathrm{~mm}$, and the particles within $1 \leq D<1.5 \mathrm{~mm}$ provide the greatest contribution to rainfall intensity. Squall line rain contains more medium raindrops. The raindrops within $1 \leq \mathrm{D}<1.5 \mathrm{~mm}$ have the largest raindrop number and provide the greatest contribution to rainfall rate. Compared with the results of Bringi, the particles of typhoon and squall line precipitation are larger and the raindrop sizes are smaller.

(2) The stratiform cloud and mixed cloud rainfall are predominant for typhoon precipitation, and convective rainfall is prevalent for squall line. The slope of $Z_{D R}$ of typhoon rain is smaller than that of squall line. The slopes of $K_{D P}$ for the two precipitation types are similar. The above results correspond to the idea that typhoon rainfall contains more small drops and squall line rainfall contains more large drops. Given that $Z_{\mathrm{H}}, Z_{D R}, K_{D P}$ and their occurrence frequencies are different for the two precipitation types, the QPE algorithms for dual-pol radar should be developed by applying different estimators according to precipitation type.

(3) For the two precipitation types, $R 1\left(Z_{\mathrm{H}}\right)$ produces the poorest precipitation estimation and $R 4\left(K_{D P}, Z_{D R}\right)$ gives the best estimation among the four estimators of the two fitting methods. The number concentration of small raindrops has a more notable impact on the $R 4\left(K_{D P}, Z_{D R}\right)$ relationship. The PFM produced higher rainfall intensity estimation than the CFM. When $K_{D P}=1^{\circ} / \mathrm{km}$, the difference of the estimated results using the PFM and CFM is the largest for $R 2\left(K_{D P}\right)$. This result provides guidance for the application of QPE estimators with polarimetric radar.

(4) The average rainfall intensities estimated using the PFM are closer than or even equal to the standard values estimated using the CFM. The CC and RMSE of the two methods are consistent. The NE calculated using the PFM decreased by at least $10.3 \%$, and the NB decreased by at least $95.4 \%$. The PFM produces more accurate precipitation estimation and better performance.

(5) Improved estimation can be achieved by employing the estimators that correspond to the precipitation type, no matter whether the estimators are derived from the CFM or PFM. The estimators fitted using the PFM can produce the best results for a specific precipitation type. The performance of the QPE algorithms improved markedly for typhoon rainfall compared with squall line. To some extent, it verifies the accuracy of QPE for dual-pol radar and the scientific nature of the fitting method for improved precipitation estimation in this study.

Author Contributions: Y.Z. (Yonghua Zhang) and L.L. conceived and designed the experiments. S.B., Z.W., Z.A., C.C., and Y.Z. (Yang Zhang) collected and analyzed the data. Y.Z. (Yonghua Zhang) and P.S. analyzed the results and prepared the manuscript. L.L. supervised the work and provided critical comments.

Funding: This work was jointly funded by the National Key R\&D Program of China (grant number 2018YFC1507401), the Natural Science Foundation of Guangdong Province (grant number 2018A030313218), the 2018 Open Research Program of the State Key Laboratory of Severe Weather (grant number 2018LASW-B08), the China Meteorological Administration Special Public Welfare Research Fund (grant number GYHY201506006), 
the Graduate Student Scientific Innovation Projects in Jiangsu Province (grant number KYLX15_0870), and the Science and Technology Projects of Guangdong Meteorological Service (grant number GRMC2018M30).

Acknowledgments: We would like to thank the Guangdong Meteorological Observation Data Center, the Guangdong Emergency Early Warning Release Center (Guangdong Weather Modification Centre), and Beijing Mestar Radar Co. Ltd for collecting and archiving the DSD data in this study.

Conflicts of Interest: The authors declare no conflict of interest.

\section{References}

1. Lin, Y.; Fujiang, Y. The long-range change and forecast of storm surge disasters in China. Chin. J. Mar. Forecasts 2002, 19, 89-96. [CrossRef]

2. Huijuan, Y.; Ning, L.; Yang, L. Features of typhoon in southeast coastal regions of China in the recent 54 years. Chin. J. Sci. Meteorol. Sin. 2007, 27, 413-418.

3. Zhang, J.X.; Ping-ri, L.I.; Guang-qing, H.; Zhang, H.O. Risk assessment of swingeing stom surge disaster in coastal area of China induced by typhoonbased on information diffusion method. Chin. J. Trop. Geogr. 2007, 27, 11-14.

4. Haiyan, N.; Min, L.; Min, L.; Ruisong, Q.; Jingjing, W.; Ning, Z. Losses assessment of typhoon disaster in China coastal areas. Chin. J. Catastrophol. 2011, 26, 61-64.

5. Rosenfeld, D.; Ulbrich, C.W. Cloud microphysical properties, processes, and rainfall estimation opportunities. Radar and Atmospheric Science: A Collection of Essays in Honor of David Atlas, Meteor. Monogr. Am. Meteor. Soc. 2003, 30, 237-258.

6. Zhang, G.; Sun, J.; Brandes, E.A. Improving parameterization of rain microphysics with disdrometer and radar observations. J. Atmos. Sci. 2006, 63, 1273-1290. [CrossRef]

7. Yujie, P.; Kun, Z.; Yinong, P.; Yiping, W. Dual-doppler analysis of a squall line in southern China. Chin. J. Acta Meteorol. Sin. 2012, 70, 736-751.

8. Hong, G.; Yonghui, L.; Miao, Z. Mesoscale analysis on a squall line in the warm-sector heavy rainfall over southern China. Chin. J. Torrential Rain Disasters 2014, 33, 171-180. [CrossRef]

9. Chong, F.; Yinjing, L.; Yancha, C.; Jie, S.; Wenjian, Z. Comparative analysis of statistical environmental characteristics between westerly squall line and typhoon squall line in south China. Chin. J. Trop. Meteorol. 2017, 33, 965-974. [CrossRef]

10. Ryzhkov, A.V.; Zrnić, D.S. Comparison of dual-polarization radar estimators of rain. J. Atmos. Ocean. Technol. 1995, 12, 249-256. [CrossRef]

11. Ryzhkov, A.V.; Zrnić, D.S. Assessment of rainfall measurement that uses specific differential phase. J. Appl. Meteorol. 1996, 35, 2080-2090. [CrossRef]

12. Zhang, G.; Vivekanandan, J.; Brandes, E. A method for estimating rain rate and drop size distribution from polarimetric radar measurements. IEEE Trans. Geosci. Remote Sens. 2001, 39, 830-841. [CrossRef]

13. Brandes, E.A.; Zhang, G.; Vivekanandan, J. Comparison of polarimetric radar drop size distribution retrieval algorithms. J. Atmos. Ocean. Technol. 2004, 21, 584-598. [CrossRef]

14. Ryzhkov, A.V.; Giangrande, S.E.; Schuur, T.J. Rainfall estimation with a polarimetric prototype of WSR-88D. J. Appl. Meteorol. 2005, 44, 502-515. [CrossRef]

15. Ryzhkov, A.V.; Schuur, T.J.; Burgess, D.W.; Heinselman, P.; Zrnić, D.S. The joint polarization experiment: Polarimetric rainfall measurements and hydrometeor classification. Bull. Am. Meteorol. Soc. 2005, 86, 809-824. [CrossRef]

16. Bringi, V.; Thurai, M.; Nakagawa, K.; Huang, G.; Kobayashi, T.; Adachi, A.; Hanado, H.; Sekizawa, S. Rainfall estimation from c-band polarimetric radar in Okinawa, Japan: Comparisons with 2D-video disdrometer and 400MHz wind profiler. J. Meteorol. Soc. Jpn. Ser. II 2006, 84, 705-724. [CrossRef]

17. Wang, Y.; Zhang, J.; Ryzhkov, A.V.; Tang, L. C-Band polarimetric radar QPE based on specific differential propagation phase for extreme typhoon rainfall. J. Atmos. Ocean. Technol. 2013, 30, 1354-1370. [CrossRef]

18. You, C.H.; Kang, M.Y.; Lee, D.I.; Uyeda, H. Rainfall estimation by S-band polarimetric radar in Korea. Part I: Preprocessing and preliminary results. Meteorol. Appl. 2014, 21,975-983. [CrossRef]

19. Matrosov, S.Y.; Cifelli, R.; Neiman, P.J.; White, A.B. Radar rain-rate estimators and their variability due to rainfall type: An assessment based on hydrometeorology testbed data from the southeastern United States. J. Appl. Meteorol. Climatol. 2016, 55, 1345-1358. [CrossRef] 
20. Montopoli, M.; Roberto, N.; Adirosi, E.; Gorgucci, E.; Baldini, L. Investigation of weather radar quantitative precipitation estimation methodologies in complex orography. Atmosphere 2017, 8, 34. [CrossRef]

21. Zhang, Y.; Liu, L.; Wen, H.; Wu, C.; Zhang, Y. Evaluation of the polarimetric-radar quantitative precipitation estimates of an extremely heavy rainfall event and nine common rainfall events in Guangzhou. Atmosphere 2018, 9, 330. [CrossRef]

22. Adirosi, E.; Roberto, N.; Montopoli, M.; Gorgucci, E.; Baldini, L. Influence of disdrometer type on weather radar algorithms from measured DSD: Application to Italian climatology. Atmosphere 2018, 9, 360. [CrossRef]

23. Wang, J.; Liu, L.; Cao, J. A comparison of methods of rainfall rate measurements by dual linear polarization Doppler radar. Chin. J. Meteorol. Mon. 2005, 31, 25-30. [CrossRef]

24. Aydin, K.; Giridhar, V. C-band dual-polarization radar observables in rain. Atmos. Ocean. Technol. 2009, 9, 383-390. [CrossRef]

25. Gu, J.Y.; Ryzhkov, A.; Zhang, P.; Neilley, P.; Knight, M.; Wolf, B.; Lee, D.I. Polarimetric attenuation correction in heavy rain at C band. J. Appl. Meteorol. Climatol. 2011, 50, 39-58. [CrossRef]

26. Wu, L. Application Study of Mobile c-Band dual-Polarization Radar Quality Control and QPE Using Raindrop Size Distribution. Ph.D. Thesis, Chinese Academy of Meteorological Sciences, Beijing, China, 2014.

27. Silvestro, F.; Rebora, N.; Ferraris, L. An algorithm for real-time rainfall rate estimation by using polarimetric radar: RIME. J. Hydrometeorol. 2009, 10, 227-240. [CrossRef]

28. Bringi, V.N.; Rico-Ramirez, M.A.; Thurai, M. Rainfall Estimation with an Operational Polarimetric C-Band Radar in the United Kingdom: Comparison with a Gauge Network and Error Analysis. J. Hydrometeorol. 2011, 12, 935-954. [CrossRef]

29. Lee, G.W. Sources of errors in rainfall measurements by polarimetric radar: Variability of drop size distributions, observational noise, and variation of relationships between $\mathrm{R}$ and polarimetric parameters. J. Atmos. Ocean. Technol. 2006, 23, 1005-1028. [CrossRef]

30. Kwon, S.; Lee, G.; Kim, G. Rainfall Estimation from an Operational S-Band Dual-Polarization Radar: Effect of Radar Calibration. J. Meteorol. Soc. Japan. Ser. II 2015, 93, 65-79. [CrossRef]

31. Qiming, C.; Boxiang, X.; Liping, L. A Study of The Relation between raininess, extinction of rain cloud and Parameters Measured by a dual linear polarization radar. Chin. J. Plateau Meteorol. 1990, 4, 347-355.

32. Hongfa, Z.; Baoxiang, X.; Zhijun, W.; Qiming, C. Study on Rainfall Measurement and Raindrop Spectra with Differential Reflectivity $Z_{\mathrm{dr}}$ Technique of Dual Linear Polarization Radar. Chin. J. Acta Meteorol. Sin. 1996, 54, 154-165. [CrossRef]

33. Liu, L.; Ge, R.; Zhang, P. A study of method and accuracy of rainfall rate and liquid water content measurements by dual linear polarization Doppler radar. Chin. J. Atmos. Sci. 2002, 5, 709-720.

34. Xueqian, M.; Wansheng, D.; Rongzhong, C.; Zhigang, W. Experiment of Rainfall Estimation Using X-Band Dual-Polarized Doppler Weather Radar. Chin. J. Plateau Meteorol. 2008, 2, 382-391.

35. Yichen, C.; Jinli, L.; Shu, D.; Debin, S.; Daren, L. Application of X-band dual polarization radar in precipitation estimation in summer of Beijing. Chin. J. Clim. Environ. Res. 2012, 17, 292-302. [CrossRef]

36. Chen, G.; Zhao, K.; Zhang, G.; Huang, H.; Liu, S.; Wen, L.; Yang, Z.L.; Yang, Z.W.; Xu, L.; Zhu, W. Improving polarimetric c-band radar rainfall estimation with two-dimensional video disdrometer observations in eastern China. J. Hydrometeorol. 2017, 18, 1375-1391. [CrossRef]

37. May, P.T.; Kepert, J.D.; Keenan, T.D. Polarimetric radar observations of the persistently asymmetric structure of tropical cyclone ingrid. Mon. Weather Rev. 2008, 136, 616-630. [CrossRef]

38. Tokay, A.; Bashor, P.G.; Habib, E.; Kasparis, T. Raindrop size distribution measurements in tropical cyclones. Mon. Weather Rev. 2008, 136, 1669-1685. [CrossRef]

39. Bringi, V.; Williams, C.; Thural, M.; May, P.T. Using dual-polarized radar and dual-frequency profiler for DSD characterization: A case study from Darwin, Australia. J. Atmos. Ocean. Technol. 647 Ser. II 2009, 84, 705-724. [CrossRef]

40. Chang, W.; Wang, T.C.; Lin, P. Characteristics of the raindrop size distribution and drop shape relation in typhoon systems in the western racific from the $2 \mathrm{D}$ video disdrometer and NCU c-band polarimetric radar. J. Atmos.Ocean. Technol. 2009, 26. [CrossRef]

41. Baojun, C.; Yuan, W.; Jie, M. Microphysical characteristics of the raindrop size distribution in Typhoon Morakot. J Trop. Meteorol. 2012, 18, 162-171. 
42. Wang, M.; Zhao, K.; Xue, M.; Zhang, G.; Liu, S.; Wen, L.; Chen, G. Precipitation microphysics characteristics of a Typhoon Matmo (2014) rainband after landfall over eastern China based on polarimetric radar observations. J. Geophys. Res. Atmos. 2016, 121. [CrossRef]

43. Bringi, V.N.; Chandrasekar, V.; Hubbert, J.; Gorgucci, E.; Randeu, W.L.; Schoenhuber, M. Raindrop size distribution in different climatic regimes from disdrometer and dual-polarized radar analysis. J. Atmos. Sci. 2003, 60, 354-365. [CrossRef]

44. Jiangping, P.; Wei, Z.; Aijun, J.; Aihui, Z.; Kefa, W. Characteristics of gamma raindrop size distribution based on the precipitation particle spectrometer. Chin. J. Sci. Meteorol. Sin. 2010, 30, 701-707. [CrossRef]

45. Tang, Q.; Xiao, H.; Guo, C.; Feng, L. Characteristics of the raindrop size distributions and their retrieved polarimetric radar parameters in northern and Southern China. Atmos. Res. 2014, 59-75. [CrossRef]

46. Jaffrain, J.; Berne, A. Experimental quantification of the sampling uncertainty associated with measurements from PARSIVEL disdrometers. J. Hydrometeorol. 2011, 12, 352-370. [CrossRef]

47. Atlas, D.; Ulbrich, C.W.; Meneghini, R. The multi-parameter remote measurement of rainfall. J. Radio Sci. 1984, 19, 3-22. [CrossRef]

48. Testud, J.; Oury, S.; Amayenc, P. The concept of "normalized" distribution to describe raindrop spectra: A tool for hydrometeor remote sensing. Phys. Chem. Earth 2000, 25, 897-902. [CrossRef]

49. Barber, P.; Yeh, C. Scattering of electromagnetic wave by arbitrarily shaped dielectric bodies. J. Appl. Opt. 1975, 14, 2864-2872. [CrossRef] [PubMed]

50. Pruppacher, H.R.; Beard, K.V. A wind tunnel investigation of the internal circulation and shape of water drops falling at terminal velocity in air. Q. J. Roy. Meteorol. Sci. 1970, 96, 247-256. [CrossRef]

51. Gorgucci, E.; Scarchilli, G.; Chandrasekar, V. A robust estimator of rainfall rate using differential reflectivity. J. Atmos. Ocean. Technol. 1994, 1, 586-592. [CrossRef]

52. Gorgucci, E.; Scarchilli, G. Application of multiparameter radar measurements to detect and est intercomparison of multiparameter radar algorithms for estimating of rainfall rate. In Proceedings of the Program 28th Conference on Radar Meterorology, Boston, MA, USA, 7-12 September 1997; p. 1348.

53. Scharfenberg, K.A.; Miller, D.J.; Schuur, T.J.; Schlatter, P.T.; Giangrande, S.E.; Melnikov, V.M.; Burgess, D.W. The joint polarization experiment: Polarimetric radar in forecasting and warning decision making. Weather Forecast. 2004, 20, 775-788. [CrossRef]

54. Gao, Y.F.; Chen, Y.D.; Gochis, D.; Ikeda, K.; Ye, J. Analysis of JPOLE algorithm with a dual polarization radar in different precipitation processes. J. Trop. Meteorol. 2014, 2, 361-366.

55. Noh, S.J.; Lim, S.; Choi, S.W.; Hwang, S.H.; Lee, D.R. Comparison of quantitative precipitation estimation algorithms using dual polarization radar measurements in Korea. J. Acoust. Soc. Am. 2014, 14, 105-116. [CrossRef]

56. Gorgucci, E.; Scarchilli, G.; Chandrasekar, V. Sensitivity of multiparameter radar rainfall algorithms. J. Geophys. Res. Atmos. 2000, 105, 2215-2223. [CrossRef]

57. Zhang, Y.; Liu, L.; Wen, H.; Chen, C.; Wang, H.; Xi, B. Development and Assessment of Quantitative Precipitation Estimation Algorithms for S-, C-, and X-band Dual-Polarization Radars Based on Disdrometer Data from Three Regions of China. J. Trop. Meteor. 2018, submitted.

(C) 2019 by the authors. Licensee MDPI, Basel, Switzerland. This article is an open access article distributed under the terms and conditions of the Creative Commons Attribution (CC BY) license (http:/ / creativecommons.org/licenses/by/4.0/). 